Revista Água Viva

\title{
TEMPO, PERSONAGEM E ESPAÇO: A VIVÊNCIA CONTEMPORÂNEA NO CONTO DE CORPO E ALMA, DE PAULO SESAR PIMENTEL
}

\section{TIEMPO, PERSONAJE Y ESPACIO: LA VIVENCIA CONTEMPORÁNEA EN EL CUENTO DE CUERPO Y ALMA, DE PAULO SESAR PIMENTEL}

\author{
Vanderley da Silva ${ }^{1}$
}

Recebido em: 28 mar. 2019

Aceito em: 30 jun. 2019

DOI 10.26512/aguaviva.v4i3.23828

RESUMO: Este artigo objetiva analisar a narrativa De corpo e Alma, publicado na coletânea O cão sem penas (2014), do escritor mato-grossense Paulo Sesar Pimentel. Pretende-se, neste estudo, dar destaque ao conteúdo temático presente nessa trama contemporânea e, em alguns elementos específicos vitais na construção do enredo como o tempo, as personagens e o espaço. Objetiva-se explicitar, que esses elementos são trabalhados de maneira que a configuração da personagem resulta da relação do espaço e dos objetos a ele ligados, assim como os demais elementos, que contribuem na construção de sentido de um texto literário.

Palavras-chave: Análise narrativa. De corpo e alma. Paulo Sesar Pimentel.

RESUMEN: Este artículo objetiva analizar la narrativa De cuerpo y Alma, publicada en la colección El perro sin plumas (2014), del escritor mato-grueso Paulo Sesar Pimentel. Se pretende, en este estudio, dar destaque al contenido temático presente en esta trama contemporánea y, en algunos elementos específicos vitales en la construcción del enredo como el tiempo, los personajes y el espacio. Se pretende explicitar, que esos elementos son trabajados de manera que la configuración del personaje resulta de la relación del espacio y de los objetos a él ligados, así como los demás elementos, que contribuyen en la construcción de sentido de un texto literario.

Palabras-clave: Análisis narrativo. De cuerpo y alma. Paulo Sesar Pimentel.

\section{CONSIDERAÇÕES INICIAIS}

\footnotetext{
1 Possui graduação em Letras - Português/Espanhol pela (FAFIJAN) Faculdade de Filosofia Ciências e Letras de Jandaia do Sul/Paraná. Pós-graduação em Informática na Educação pela Faculdades Integradas de Várzea Grande (FIVE), mestrando em Estudos Literários no Programa de Pós-Graduação em Letras (PPGLETRAS) pela Universidade do Estado de Mato Grosso (UNEMAT), Campus de Sinop-MT. É Professor concursado em Língua Portuguesa na Rede Estadual de Mato Grosso, lotado na Escola Estadual 12 de Abril em Terra Nova do NorteMT. E-mail: vanderleydasilva2009@hotmail.com
} 
$\mathrm{Na}$ chamada literatura contemporânea, temos uma narrativa ressaltando a liberdade formal, a valorização do cotidiano, a reescrita de textos do passado, o interesse pelo homem comum e a ordem social. As imagens são modeladas no entrelace da linguagem cotidiana e a literatura torna-se cada vez mais subjetiva, interiorizada, abstrata, construída de experiências mentais, da vida e espírito.

A partir desta fase, observam-se escritores que apresentam em suas obras traços subjetivos. Desvelando o íntimo do indivíduo, seus questionamentos e sua realidade social cotidiana, por meio de uma prosa existencial e concentrada em solo urbano, como o estilo de inovação introduzido na literatura nacional por Clarice Lispector.

Revela-se ainda, grandes autores como João Antônio, Rubem Fonseca, Lygia Fagundes Telles, Guimarães Rosa, entre outros. Tais desenvolvem narrativas curtas, revelando uma denúncia social ou apresentando personagens que ultrapassam as fronteiras da realidade.

A modernidade deixa de ser o lugar para as narrações de grandes ações e passa a expressar o mal-estar do sujeito e das experiências vividas por ele. Segundo Schollhammer (2009, p. 10) “o escritor contemporâneo parece estar motivado por uma grande urgência em se relacionar com a realidade histórica, estando consciente, entretanto, da impossibilidade de captá-la na sua especificidade atual, em seu presente".

Deste modo, visualiza-se nas obras literárias contemporâneas a retratação da realidade atual da sociedade, por meio de pontos de vistas marginais e periféricos; com uma escrita realista, que materializa a loucura, combina à profundidade psicológica com a introspecção, tornando a prosa mais existencial e intimista:

$\mathrm{Na}$ contemporaneidade identifica-se conto, como uma narrativa intensa de efeito imediato que seduz pela sua pequena extensão e pelo efeito arrebatador que provoca nos leitores e talvez, seja o gênero de maior destaque, em termos de vigor e criatividade na ficção contemporânea.

Os escritores contemporâneos buscam retratar em suas obras a realidade atual da nossa sociedade através de pontos de vista marginais e periféricos com uma escrita que materializa a loucura; que traz a profundidade psicológica e a introspecção, "literatura do eu" com uma prosa mais existencial e intimista:

Diríamos, inicialmente, que o novo realismo se expressa pela vontade de relacionar a literatura e a arte com a realidade social e cultural da qual emerge, incorporando essa realidade esteticamente dentro da obra e situando a própria produção artística como força transformadora (SCHOLLHAMMER, 2009, p. 54) 
Em meio a esse universo de escritores da literatura contemporânea produzida no Brasil, Paulo Sesar Pimentel vem ganhando significativo destaque, com um trabalho de escrita que serve de exemplo à atual literatura manifesta em Mato Grosso. Em suas narrativas, os temas do cotidiano envolvem os leitores numa leitura dinâmica de reflexão sobre o comportamento do sujeito na atualidade:

Percebe-se, nos escritores da geração mais recente, a intuição de uma impossibilidade, algo que estaria impedindo-os de intervir e recuperar a aliança com a atualidade e que coloca o desafio de reinventar as formas históricas do realismo literário numa literatura que lida com os problemas do país e que expõe as questões mais vulneráveis do crime, da violência, da corrupção e da miséria. (SCHOLLHAMMER, 2009, p. 14)

Dessa forma, o contista apresenta características da contemporaneidade em sua narrativa, mostrando a visão de um mundo conturbado, cheio de interrogações, expondo a complexidade que o ser humano enfrenta nesse mundo capitalista, egocêntrico e o estado físico e emocional do indivíduo.

\section{CONVIVIVENDO COM OS DISSABORES DA VIDA}

De corpo e alma é um conto contemporâneo dedicado a Haya Del Bel; premiado pelo $12^{\circ}$ Concurso de Contos "Josué Guimarães" (2011) e publicado na obra $O$ cão sem penas (2014). Paulo Sesar Pimentel trabalha com a temática das violências sofridas pelas personagens no mundo contemporâneo como: a angústia; a solidão marcada pela ansiedade, tensão e expectativa de liberdade.

O conto estudado apresenta uma narrativa intimista em primeira pessoa, que se constrói pela vocalização de um narrador-protagonista, fazendo um mergulho profundo na realidade que vive, não apresentando um acontecimento significativo expresso claramente que desencadeia um conflito ou tensão, porque a narrativa é bastante descritiva.

$\mathrm{O}$ autor apresenta-nos um narrador-personagem preso dentro de uma casa e às lembranças que ela traz. Perambulando pelos cômodos, buscando uma saída, pensa nos meios de escapar, mas sente medo do que poderá encontrar lá fora e teme a morte. Tal personagem relembra os acontecimentos rotineiros em sua casa, desde que ela era nova. Lembra as pessoas que ali frequentavam, de todos os espaços, de cada detalhe, cada porta, cada parede, cada 
cômodo. Descreve como são os móveis, lembra das coisas gostosas feitas em sua cozinha e da movimentação das pessoas passeando pelo jardim.

Mas, o tempo passa, a casa fica velha e tudo muda. As paredes agora sujas, móveis estragados, um vazio instalado. Não há nada para comer e ninguém para conversar. Com tanto sofrimento, o narrador-personagem vive uma tristeza profunda, carregada de uma vontade de se libertar daquela prisão. Ele sabe onde é a porta de saída, sabe como mover a maçaneta da porta e sair, mas se sente preso a algo que o impede de fazê-lo, talvez por medo, ou porque tem a missão de contar e separar todas as sementes que entram na casa todo momento.

O herói da narrativa sabe que é impossível fazer a contagem dos grãos acumulados, mas tem esperanças de que, um dia, irá sair daquela casa, onde passou toda sua vida. Sonha em ter uma vida simples, para, talvez, plantar um jardim, ou apenas cultivar uma árvore, cuidar de uma flor, ou sentar em uma cadeira de descanso na varanda e esperar passar o pouco de tempo, que ainda lhe resta.

Elaborado mediante uma linguagem vivaz, percebe-se nessa narrativa a habilidade e a sutileza empregadas pelo autor numa escrita repleta de metáforas. Na escolha dos temas faz-se possível a revelação de um olhar sensível e crítico sobre as relações sociais no contexto contemporâneo.

Encontra-se o tema 'medo', presente na narrativa, transmitindo às personagens, consequentemente aos leitores, uma sensação poderosa. Conduz a um estado de alerta e de receio a uma ação ou mudança, a algo que lhes ameace física e/ou psicologicamente.

Para Bauman (2008), o medo na pós-modernidade é assustador, pois vem carregado de incertezas, é difuso, não está delimitado, é fragmentado e pode surgir de qualquer lugar. Causa insegurança generalizada diante do sentimento de incapacidade para lidar com problemas complexos que acompanham o ser humano rotineiramente:

O medo é mais assustador quando difuso, disperso, indistinto, desvinculado, desancorado, flutuante, sem endereço nem motivo claros; quando nos assombra sem que haja uma explicação visível, quando a ameaça que devemos temer pode ser vislumbrada em toda parte, mas em lugar algum se pode vê-la. "Medo" é o nome que damos a nossa incerteza: nossa ignorância da ameaça e do que deve ser feito - do que pode e do que não pode - para fazê-la parar ou enfrentá-la, se cessá-la estiver além do nosso alcance (BAUMAN, 2008, p. 08).

Verifica-se tal sentimento, visto que a personagem busca se refugiar nas suas lembranças e fantasias, onde ao mesmo tempo em que deseja sair de um mundo demarcado pelo 
sofrimento, teme a mudança: "Sei mover a chave na fechadura, acho que sei, acho que não esqueci. Vou ignorar os passos e o medo. Vou ignorar os grãos que se acumularam, que se acumulam, e vou sair" (PIMENTEL, 2014, p. 13).

A presença do tema 'abandono' inserido na trama, proporciona um sentimento carregado negativamente e melancólico, fazendo o leitor mergulhar na realidade em que vive a personagem-principal. Uma realidade solitária e de abandonos. Nota-se que o protagonista parece insatisfeito com o seu estado: "Prefiro acreditar, no entanto, que há ainda gente nas ruas, ainda existem pessoas que passam e que não estou tão sozinho aqui dentro, largado ao próprio azar, esperando que qualquer pessoa bata à porta, entre e traga um pouco de luz" (PIMENTEL, 2014, p. 10-11).

Observa-se que o tema 'prisão' também se mostra presente na narrativa, já que o narrador-personagem declara viver preso em seu domicílio sem conseguir sair, deseja fugir, porém não pode devido a árdua tarefa de cuidar da casa e contar as sementes que nela entram a todo instante: Estou preso. Tenho que contar todos os grãos, cada parte, trocar as facetas, cuidar das goteiras e ouvir os passos lá fora (PIMENTEL, 2014, p. 13).

\section{ENTENDENDO A PLURALIIDADE DO TEMPO}

O tempo tem papel imprescindível em uma narrativa com a função de nos manter situados, de maneira que possamos entender melhor os fatos. Benedito Nunes (1995, p. 14), afirma que o tempo é uma arte da narrativa que possui três planos: o da história; o do discurso e o da narração. Nas palavras do autor "O texto narrativo possui encadeamentos de ordem temporal, conforme a sucessão dos fatos que o discurso evoca".

Gérard Genette (1995) faz um estudo da importância do tempo no discurso das narrativas e de suas supostas ocorrências. Para ele, o tempo serve para mostrar os fenômenos, os efeitos de ordem, duração, frequência, direção, marcação, ritmo, modo e voz, que estão explícitos ou implícitos no texto, sendo o tempo responsável na definição de muitas ações em uma história:

Enquanto o tempo físico se traduz com mensurações precisas, que se baseiam em estalões unitários constantes, para o cômputo da duração, o psicológico se compõe de momentos imprecisos, que se aproximam ou tendem a fundir-se, o passado indistinto do presente, abrangendo, ao sabor de sentimentos e lembranças, intervalos incomparáveis (NUNES, 1995, p. 19). 
De acordo com o autor, percebe-se que os elementos de ordem temporal predominam com base no tempo psicológico, visto que no primeiro momento, o narrador-personagem usa o recurso da analepse. Esse artifício trata-se de "toda a ulterior evocação de um acontecimento anterior ao ponto da história em que se está" (GENETTE, 1995, p. 38). Nesse caso, a voz enunciadora faz o movimento retrospectivo, começa a narrativa no presente, momento que se sente próximo do fim e, por meio de suas lembranças volta ao passado. Essa mudança pode ser verificada pelo uso de tempo verbal que indica tempo presente ("Moro") e outro que indica tempo passado (“Foram”).

Em outra passagem da narrativa há a referência ao tempo cronológico: "Só pensando, afinal, meu tempo passou a tanto tempo (meses, anos, décadas), que dentro só restam grãos, migalhas separadas, contadas, mas para sempre só migalhas do que veio de fora eu deixei entrar" (PIMENTEL, 2014, p. 14). Aqui, o recurso de duração da narrativa permeia-se pela elipse explícita por meio do tempo decorrido em "meses, anos e décadas", ou seja, tempos que não voltam mais.

Ao "contar uma vez aquilo que se passou uma vez" (GENETTE, 1995, p. 114) ocorre uma frequência singulativa. Faz-se possível constatar uma narrativa de determinação, visto que o narrador marca o início e o término de uma série:

No quarto, lembro-me apenas de um, havia uma cama macia, dois travesseiros, um lençol sempre branco, que abraçava forte o corpo, com a suavidade que acalentava o sono. Havia tanta coisa bonita, tanta coisa gostosa, mas só quando essa casa era nova (PIMENTEL, 2014, p. 09).

A expressão "só quando a casa era nova" marca o tempo da mudança ocorrida na casa. No segundo momento da narrativa o tempo predominante vem a ser o simultâneo, tempo vivo, pois está narrado no presente: "Todos os dias alguém passa e joga grãos" (PIMENTEL, 2014, p. 10).

Isso posto, vê-se que as essas modalidades de tempo têm em comum o fato de que elas aplicam-se às noções de ordem, duração e direção dos acontecimentos, sendo o "tempo", responsável por definir muitas das ações que acontecem em uma história; está presente na narração e no discurso dos personagens, influenciando a maneira como os fatos são apresentados aos leitores.

\section{CARACTERIZANDO O HERÓI DA NARRATIVA}


O texto narrativo apresenta uma entidade literária que vive a ação narrada exercendo papéis essenciais na história, ou seja, vários personagens que são os elementos vitais na construção do enredo deste tipo de texto, atuando no seu interior para praticar as ações entrelaçando atitudes, comportamentos, sentimentos e suas histórias em um tempo e um espaço:

Na vida, estabelecemos uma interpretação de cada pessoa, a fim de podermos conferir certa unidade a sua diversificação essencial, à sucessão dos seus modos-de-ser. No romance, o escritor estabelece algo mais coeso, menos variável, que é a lógica da personagem. [...] O escritor lhe deu, desde logo, uma linha de coerência fixada para sempre, delimitando a curva de sua existência e a natureza do seu modo-de-ser. (CANDIDO, 1968, p. 68-59).

Ao ler De corpo e Alma, percebe-se o narrador-personagem. Uma personagem heroína e que está mais perto do universo narrado. Por conta disso, esse tipo de narrativas está sob a ótica da personagem mediante as suas impressões, seus desejos particulares e seus sentimentos intensos.

Desta forma, Pimentel denuncia os problemas existenciais das personagens por meio da análise psicológica do sujeito na modernidade, mostrando seu caos interior e a aridez do mundo real. A partir das personagens o leitor vai confrontando suas percepções sobre o outro e o mundo, principalmente em relação à figura do protagonista, pois o herói é “o personagem que recebe a carga emocional mais viva e acentuada [por isso é] seguido pelo leitor com a maior atenção. Provoca a compaixão, a simpatia, a alegria e a tristeza do leitor" (TOMACHEVSKI, 1976, p. 195).

Nessa narrativa, o narrador-personagem relata seus sofrimentos diante do mundo moderno sob um ponto de vista próprio. Sendo assim, a caracterização da personagem inferese pelo leitor a partir das ações, atitudes e comportamentos do narrador e de outras personagens.

Dessa forma, a personagem principal, herói da narrativa pode ser identificada como um homem casmurro, egocêntrico, fechado em seus próprios pensamentos, velho, saudosista e conservador: "Moro em uma casa velha, com paredes que um dia foram caiadas de branco reluzente, na época em que havia um jardim com flores muito cuidadas, podadas, repletas das cores que compõem um arco-íris” (PIMENTEL, 2014, p. 09).

Essa personagem insegura identifica-se com o sujeito atual, visto que no mundo contemporâneo proliferam-se as dúvidas, sejam referentes ao futuro e/ou ao desconhecido: "Estou preso a essas paredes e sei onde é a porta, sei onde é a maçaneta, sei como movê-la, mas continuo aqui, contando grãos, contando areia" (PIMENTEL, 2014, p. 13). Além disso, a 
personagem, devido a uma dada situação, se tornou ansiosa e obsessiva para com a tarefa que lhe foi atribuída: "Algo me prende aqui, uma vontade, uma obsessão, uma necessidade doida de vagar, transitar, vislumbrar, lobrigar o mundo" (PIMENTEL, 2014, p. 13).

Adiante, no conto a personagem é construída sem identidade própria, com ausência de nome, idade e profissão, sendo referida por meio dos pronomes pessoais. Fato que reforçam o esvaziamento identitário, a caracterização de indivíduo coisificado, que não consegue construir laços de amizade e respeito.

No mundo moderno, às vezes, o sujeito se esconde atrás dos muros criados pela própria mente para se defender das frustrações da vida. Por mais que o indivíduo saiba que cometeu um erro, sua mente ativa mecanismos defensores que tentam encontrar maneiras de fazer com que ele escape da culpa:

Em nosso mundo de 'individualização' em excesso, as identidades são bênçãos ambíguas. Oscilam entre o sonho e o pesadelo, e não há como dizer quando um se transforma no outro. Na maior parte do tempo, essas duas modalidades líquido-modernas de identidade coabitam, mesmo que localizadas em diferentes níveis de consciência (BAUMAN, 2005, p. 38).

Diante do exposto, entende-se que o herói dessa trama apresenta características do sujeito contemporâneo, pois convive com os dramas e conflitos do tempo presente.

\section{QUALIFICANDO O ESPAÇO DA TRAMA}

O espaço numa narrativa muitas vezes é variado, vão desde um lugar fechado a lugares abertos. Em muitos casos o espaço adquire grande importância para o desenvolvimento da narrativa, passando, às vezes, a ser fundamental dentro da trama. No ambiente, que é o espaço social pelo qual circulam as personagens, com suas atmosferas interiores carregados de características psicológicas:

O espaço integra em primeira instância, os componentes físicos que servem de cenário ao desenrolar da ação e a movimentação das personagens; em segunda instância, o conceito de espaço pode ser entendido em sentido translato, abarcando então tanto as atmosferas sociais (espaço social) como até as psicológicas (espaço psicológico). (REIS E LOPES, 1988, p. 204).

Assim, a citação acima reafirma o fato de que não cabe ao espaço desempenhar o papel de simples lugar onde se desenvolve a narrativa. Em seu lado físico faz-se possível conhecer o 
local, dos detalhes mais ínfimos aos mais relevantes, por meio da descrição oferecida pelo narrador, sendo passível o levantamento de características que levam ao reconhecimento de um espaço fechado ou aberto, urbano ou rural, entre outros.

Em relação a sua outra face, o espaço social e psicológico compõe-se pelos distintos lugares pelos quais circulam as personagens, sujeitos carregados de complexidades e cujo interior vão se desvestindo num fluxo de pensamentos e sentimentos. Trata-se de um espaço onde há "[...] um conjunto de processos conhecidos ou possíveis, destinados a provocar, na narrativa, a noção de um determinado ambiente" (LINS, 1976, p. 77).

Percebe-se que a trama do conto estudado se desenvolve na casa do narradorpersonagem, local onde o sujeito sente-se acolhido e protegido em sua intimidade, pautando-se no fato de que "a casa é uma das maiores forças de integração para os pensamentos, as lembranças e os sonhos do homem" (BACHELARD, 1993, p. 26).

Em conformidade com a características da escrita da narrativa contemporânea, esse local situa-se em um contexto urbano, no lar onde a personagem vive infeliz, melancólica, presa às boas recordações do passado interligadas ao local:

Essa casa que era nova, onde ainda moro, hoje tem paredes manchadas de um bolor escuro, não se sabe onde parede, onde bolor. Não sei mais nada do jardim, pois nunca saio, não olho para fora, não tenho tempo, com tantos grãos que invadem por todas por todas as frestas (PIMENTEL, 2014, p. 10).

Observa-se que ao descrever a casa com "paredes manchadas com bolor escuro" o narrador-personagem cria um paralelo às relações temporais e espaciais apresentando as mudanças sofridas no local.

A transformação do espaço, reafirmada pelo aparecimento de manchas escuras perpetuadas ao decorrer dos anos e transpassada explicitamente no discurso da personagem, caracteriza o espaço temporal na arte do cronotopo que para Bakhtin (2010, p. 211) ocorre quando "os índices do tempo transparecem no espaço, e o espaço reveste-se de sentidos e é medido com o tempo".

Desta forma, o espaço físico da narrativa - agora degradado - potencializa o surgimento de lembranças da/na personagem, que sente saudades do tempo passado, ou seja, do tempo morto, outrora um período agradável:

No quarto, lembro-me apenas de um, havia uma cama macia, dois travesseiros, um lençol sempre branco, que abraçava forte o corpo, com uma 
suavidade que acalentava o sono. Havia tanta coisa bonita, tanta coisa gostosa, mas só quando essa casa era nova (PIMENTEL, 2014, p. 09).

Cabe a ressalva de que no decorrer da citação acontece uma mudança significativa do espaço íntimo da personagem em detrimento ao tempo que passou. Em primeiro momento, o quarto é descrito com seus objetos em perfeitas condições, mostrando a vivência e a intimidade do narrador para com o local, desencadeando sentimentos e lembranças perduráveis por toda a vida.

A referência a "cama macia" gera a ideia de um lugar aconchegante, onde a personagem desfrutava de uma boa e tranquila noite de sono e cujo repouso, possivelmente, acarretava uma melhor disposição e humor para o dia seguinte. A frase "um lençol sempre branco" evidencia a limpeza e a pureza do lugar, fatos avigorados pela utilização e menção da cor branca, podendo simbolizar ainda a paz que a personagem desfrutava naquele ambiente antes do afinamento do tempo:

Durmo no mesmo quarto em que, outrora, os lençóis brancos me acariciavam. Agora, brigo cotidianamente com trapos que não aceitam minha pele e meu sono é agitado e perverso, regido por meus braços que, mesmo eu dormindo, continuam catando os grãos que invadem a casa (PIMENTEL, 2014, p. 10).

No segundo momento, há o jogo que o narrador faz com o tempo no espaço. A transformação do quarto, agora velho e com os seus objetos estragados, deixam o local com a aparência de uma casa abandonada pelos moradores. Os "trapos", em um passado longínquo, lençóis, aparecem para caracterizar a decadência do espaço físico, algo gasto pelo tempo, um pedaço de pano velho e inadequado a pele, mudando a sensação de aconchego e tranquilidade para desassossego e angústias.

Seguindo adiante, faz-se possível constatar certa agitação por parte da personagem que ao perambular pelos cômodos da casa, buscando uma saída, apreende o passar do tempo. A influência do espaço, relacionado ao tempo, faz tanto sentido para o protagonista que ele se compara a casa no momento em que constata que envelheceu junto a ela, abrindo margem a impressão de abandono, feiura e inutilidade: "Só pensando, afinal, meu tempo passou há tanto tempo (meses, anos, décadas), que dentro só restam grãos, migalhas, separados, contadas, mas para sempre só migalhas do que veio de fora e eu deixei entrar" (PIMENTEL, 2014, p. 10). 
Contudo, percebe-se que os espaços da trama são elementos organizadores no enredo e a vários aspectos que estão relacionados às narrativas da ficção, como à personagem, ao tempo e a todos os demais elementos estruturais do texto narrativo.

\section{CONSIDERAÇÕES FINAIS}

Objetivou-se nesse trabalho, dar destaque ao conteúdo temático e os elementos da narrativa mostrando como estes, contribuem para a construção de sentido da obra.

Diante disso, conclui-se que as modalidades temporais empregadas na narrativa, bem como o tempo psicológico, o tempo linguístico, o tempo físico e o tempo cronológico, servem para situar as personagens na questão de ordem e, de duração dos acontecimentos no enredo.

Averiguou-se também que os personagens de Pimentel apresentam características do sujeito contemporâneo, dado que convivem com os dramas e conflitos do tempo presente. São, pois seres fictícios capazes de prender o leitor e levá-los a acreditar que a situação narrativa é verossímil. De acordo com Candido (2011), as grandes personagens agem de modo a emocionar e a impressionar, considerando que a força vem do fato de que o sentimento que temos da sua complexidade é máximo; mas isso, devido à unidade, à simplificação estrutural que o romancista lhe deu.

Atestou-se ainda que os espaços construídos na obra, são elementos organizadores e que não se imbricam somente a lugares em que se passam as ações, mas também a vários aspectos que estão relacionados às narrativas da ficção, como à personagem, ao tempo, à ação, à focalização e à estrutura do texto narrativo.

\section{REFERÊNCIAS}

BACHELARD, Gaston. A poética do espaço. Tradução Antônio da Costa Leal e Lídia do Valle Santos Leal. São Paulo: Martins Fontes, 1993.

BAKHTIN, Mikhail. Questões de Literatura e de Estética - A Teoria do Romance. 6 edição.São Paulo, HUCITEC, 2010.

BAUMAN, Zygmunt. O Medo Líquido. Tradução Carlos Alberto Medeiros. Rio de Janeiro: Jorge Zahar, 2008.

BAUMAN, Zygmunt. Identidade. Entrevista a Benedetto Vecchi. Rio de Janeiro: J. Zahar, 2005. 
Revista Água Viva

BOSI, Alfredo. O conto brasileiro contemporâneo. São Paulo: Cultrix-USP, 1974.

CANDIDO, Antonio et al. A Personagem de ficção. 2. ed. São Paulo: Perspectiva, 1968.

GENETTE, Gérard. Discurso da narrativa. Lisboa: Vega, 1995.

LINS, Osman. Lima Barreto e o espaço romanesco. São Paulo: Ática, 1988.

NUNES, Benedito. O tempo na narrativa. São Paulo, Ática, 1995.

PIMENTEL, Paulo Sesar. O cão sem penas. Mato Grosso: Carlini \& Caniato, 2014.

REIS, Carlos; LOPES, Ana Cristina M. Dicionário de teoria narrativa. São Paulo: Ática, 1988.

SCHOLLHAMMER, Karl Erik. Ficção brasileira contemporânea. Rio de Janeiro: Civilização Brasileira, 2009.

TOMACHEVISKI, B. Temática. In: EIKHENBAUM, B. et al. Teoria da literatura: formalistas russos. 3 ed. Porto Alegre: Globo, 1976, p. 169-204. 